\title{
PHOTOCHEMISTRY OF ORGANOPOLYGERMANES CONTAINING GERMANIUM CATENATES
}

Kunio Mochida

Department of Chemistry, Faculty of Science, Gakushuin University, 1-5-1 Mejiro, Tokyo 171, Japan

\begin{abstract}
Recent works on polygermanes containing germanium catenates are summarized and reviewed.

Photochemical reactions of polygermanes containing germanium catenates have been investigated by mercury photolysis, laser-flash photolysis, and matrix isolation techniques. All of the polygermanes proceed by both the extrusion of germylenes and the homolytic scission of germanium-germanium bond.
\end{abstract}

\section{Linear Permethylpolygermanes}

Linear permethyloligogermanes, $\mathrm{Me}\left(\mathrm{Me}_{2} \mathrm{Ge}\right)_{n} \mathrm{Me}(\mathrm{n}=3-6)$ in cyclohexane are irradiated with a low-pressure $\mathrm{Hg}$ arc lamp. Octamethyltrigermane is always produced as a major product together with unindetified high-boiling products (Table 1). The trigermane is very resist to the photoylsis under the conditions used [1].

Table 1. Photolysis of Permethyloligogermane, $\mathrm{Me}\left(\mathrm{Me}_{2} \mathrm{Ge}\right)_{n} \mathrm{Me}(\mathrm{n}=3-6)$ in Cyclohexane

\begin{tabular}{|c|c|c|c|c|c|}
\hline \multirow[b]{2}{*}{ Polygermane } & \multirow[b]{2}{*}{$\lambda \max / \mathrm{nm}$} & \multirow[b]{2}{*}{ Conversion/\% } & \multicolumn{3}{|c|}{ Products (Yield/\%) } \\
\hline & & & 1 & 2 & 3 \\
\hline $\begin{array}{c}\mathrm{Me}\left(\mathrm{Me}_{2} \mathrm{Ge}\right)_{3} \mathrm{Me} \\
1\end{array}$ & 217.5 & 2.6 & & & \\
\hline $\begin{array}{c}\mathrm{Me}\left(\mathrm{Me}_{2} \mathrm{Ge}\right)_{4} \mathrm{Me} \\
2\end{array}$ & 232.5 & 39.7 & 66.7 & & \\
\hline $\begin{array}{c}\mathrm{Me}\left(\mathrm{Me}_{2} \mathrm{Ge}\right){ }_{5} \mathrm{Me} \\
3\end{array}$ & 245.5 & 75.4 & 4.0 & 41.9 & \\
\hline $\begin{array}{c}\mathrm{Me}\left(\mathrm{Me}_{2} \mathrm{Ge}\right)_{6} \mathrm{Me} \\
4\end{array}$ & 222.0 & 92.3 & 8.2 & 10.9 & 25.3 \\
\hline
\end{tabular}


The contraction of the germanium-germanium chain of $\mathrm{Me}\left(\mathrm{Me}_{2} \mathrm{Ge}\right)_{n} \mathrm{Me}(\mathrm{n}=3-6)$, to produce octamethyltrigermane may be explained as a result of the extrusion of dimethylgermylene and the formation of permethylated oligogermyl radicals.

The reactive species such as dimethylgermylene and permethylated oligogermyl radicals can be detected by use of trapping experiments, matrix isolation, and ESR techniques.

Irradiation of permethylated oligogermanes in the presence of 2,3-dimethylbutadiene affords 1-germacyclopentenes. Similar photolysis of the oligogermanes in the presence of $\mathrm{CCl}_{4}$ produces dimethyldichlorogermane and permethylated oligogermyl chlorides. The presence of 1-germacyclopentenes [2] and dimethyldichlorogermane [3,4] indicates intermediacy of dimethylgermylene. The formation of oligogermyl chlorides is indicative of the presence of an intermediate form of oligogermyl radicals generated by homolysis of the germanium-germanium bond of the oligogermanes [5].

UV irradiation for permethylated oligogermanes in 3-methylpentane at $77 \mathrm{~K}$ produces yellow glasses with broad band at $430-440 \mathrm{~nm}$ due to dimethylgermylene. The unsymmetrical ESR signals (ca g=2.014) due to some organogermyl radicals are also observed in the photolysis of the oligogermanes at $77 \mathrm{~K}[6]$.

On the basis of this evidence, photochemical degradation of permethylated linear oligogermanes, $\mathrm{Me}\left(\mathrm{Me}_{2} \mathrm{Ge}\right)_{n} \mathrm{Me}(\mathrm{n}=3-6)$ may be rationalized on the basis of Scheme 1.

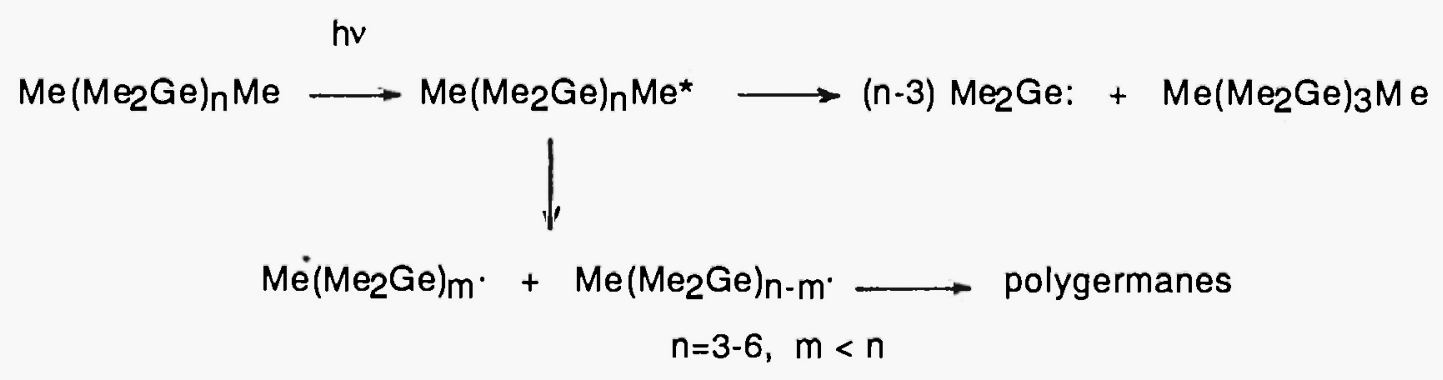

\section{Scheme 1}

The photolysis of a number of substituted high molecular weight polygermanes similarly involves both germanium-germanium bond homolysis to give polygermyl radicals and the extrusion of germylenes as described in case of oligogermanes. [7].

High molecular weight polygermanes, $\left(\left(\mathrm{Et}_{2} \mathrm{Ge}\right)_{n},\left(\mathrm{n}-\mathrm{Bu} \mathrm{G}_{2} \mathrm{Ge}\right)_{\mathrm{n}},\left(\mathrm{n}-\mathrm{Hex}_{2} \mathrm{Ge}\right)_{n}\right.$, and (PhMeGe)n), in cyclohexane are irradiated with a low-pressure $\mathrm{Hg}$ arc lamp to produce lower molecular weight chain fragments by chain scission (Fig. 1). These phenomena are investigated by laser flash-photolysis and trapping experiments.

Laser-flash photolysis of high molecular weight polygermanes gives two-well separated 
transient absorption bands at $350-370 \mathrm{~nm}$ and $430-460 \mathrm{~nm}$. The transient peak at longer wavelengths (430-460 nm) may be assigned to that of a germylene from comparison of its spectral characteristics with those of similar germylenes reported [4,8-12]. On the other hand, the transient peak at shorter wavelengths $(350-370 \mathrm{~nm})$ may be assigned to polygermyl radicals by comparison of their spectral characteristics with those reported for similar germyl radicals [10,13-15].

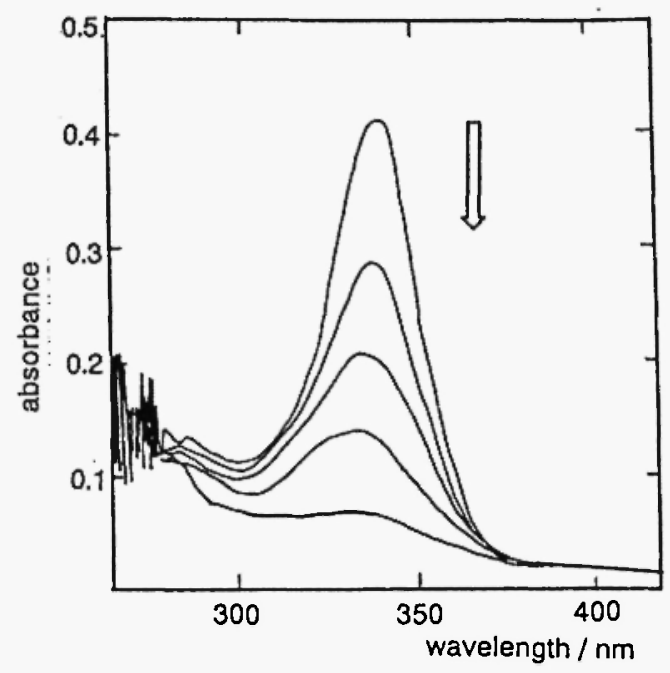

Fig. 1. UV absorption spectra of $\left(n-\mathrm{Hex}_{2} \mathrm{Ge}\right)_{n}\left(\mathrm{Mw}=11.5 \times 10^{3}\right)$ in cyclohexane with successive irradiation.

Product studies are carried out by photolyzing polygermanes in cyclohexane containing $\mathrm{CCl}_{4}$ with a $110-\mathrm{W}$ low-pressure $\mathrm{Hg}$ arc lamp. Dichlorogermanes and hexachloroethane are obtained as the main products. The presence of dichlorogermanes and hexachloroethane seems to indicate the intermediacy of germylenes and polygermyl radicals, respectively.

On the basis of this study the mechanism shown in Scheme 2 is proposed.

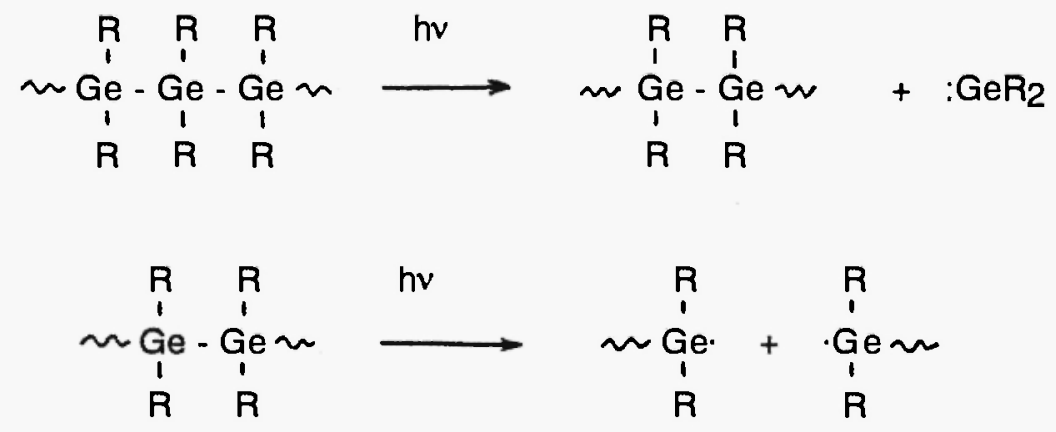

$\left(\mathrm{R}_{2} \mathrm{Ge}\right)_{n}:\left(\mathrm{Et}_{2} \mathrm{Ge}\right)_{n}, \overline{\mathrm{M}}_{\mathrm{W}}=3.4 \times 10^{3},\left(\mathrm{n} \cdot \mathrm{Bu}_{2} \mathrm{Ge}\right)_{n}, \bar{M}_{W}=4.1 \times 10^{3}$, $\left(\mathrm{n}-\mathrm{Hex}_{2} \mathrm{Ge}\right)_{n}, \bar{M}_{W}=11.5 \times 10^{3},(\mathrm{PhMeGe})_{n}, \mathbb{M}_{W}=5.0 \times 10^{3}$ 


\section{Cyclic Alkyl-substltuted Polygermanes}

Photolysis of dodecamethylcyclohexagermane in cyclohexane at room temperature proceeds readily with loss of dimethylgermylene to give two of the lower homologs, decamethylcyclopentagermane and octamethylcyclotetragermane [9]. The photochemically generated dimethylgermylene reacts with 2,3-dimethylbutadiene and $\mathrm{CCl}_{4}$ to give 1-germacyclopentene and dimethyldichlorogermane, respectively. The transient absorption of the cyclohexagermane in cyclohexane at $450 \mathrm{~nm}$ obtained by laser flash photolysis is due to dimethylgermylene. In 3-methylpentane glass dimethylgermylene shows an absorption band at $430 \mathrm{~nm}$ and a fluorescence peak at $650 \mathrm{~nm}$. The photo-generated germylene appears to be the singlet state.

The irradiation of decamethylcyclopentagermane in cyclohexane with a $110 \mathrm{~W}$ low-pressure $\mathrm{Hg}$ arc lamp to give octamethylcyclotetragermane together with several prodcuts. The generation of dimethylgermylene accompanied by ring contraction is characterized by use of trapping experiments, laser flash photolysis, and matrix isolation [16].

Therefore, the ring contraction mechanism of cyclohexagermane is shown in Scheme 3.

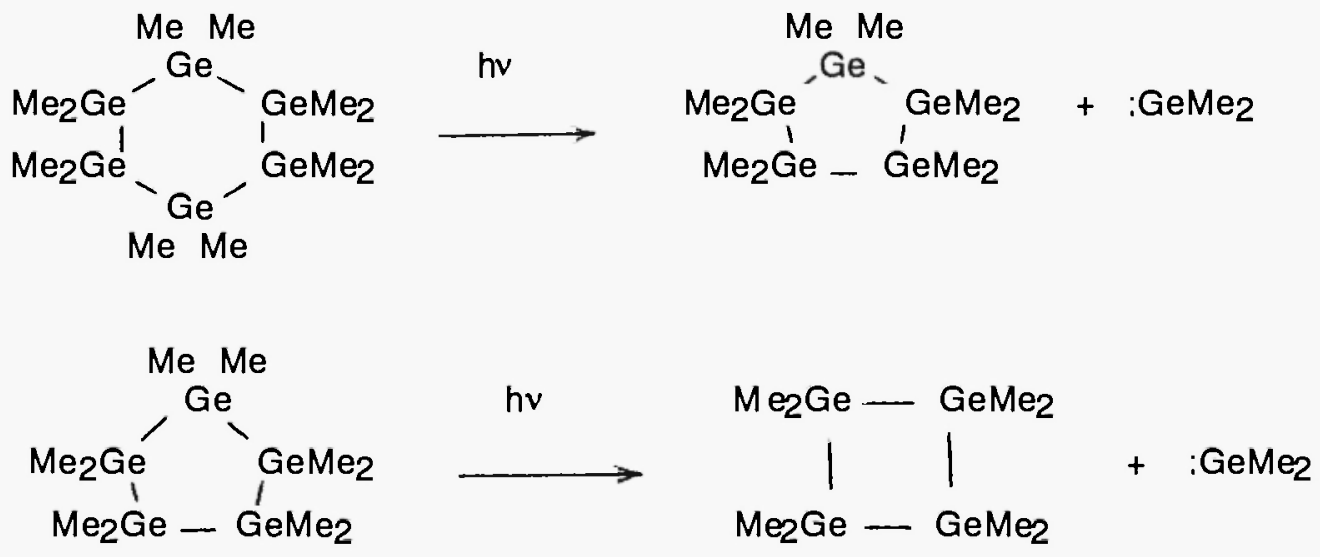

\section{Scheme 3}

Non-planar octaisopropylcylotetragermane also undergos photolysis when this cyclohexane solution is irradiated with a low-pressure $\mathrm{Hg}$ arc lamp [17,18]. Together with highboiling unidentified products, dihydroteragermane, dihydrotrigermane, and dihydrodigermane are formed in the photolysate. The dihydrotetragermane is likely to arise from the cyclotetragermane, which undergoes ring opening to form the intermediate tetragermyl diradical. - The tetragermyl diradical in turn abstracts hydrogen from hydrogen sources. The dihydrotrigermane is explained by the intermediacy of the trigermyl diradical. The trigermyl diradical, 
which forms from ring opening of the cyclotrigermane or from the tetragermyl diradical by $\alpha$ elimination of a germylene, abstracts hydrogen [8]. The dihydrodigermane seems to arise from the intermediacy of the digermene abstracting hydrogen.

The intermediacy of germylene suggested by photo-products is also detected by laser flash photolysis and matrix isolation techniques.

path a

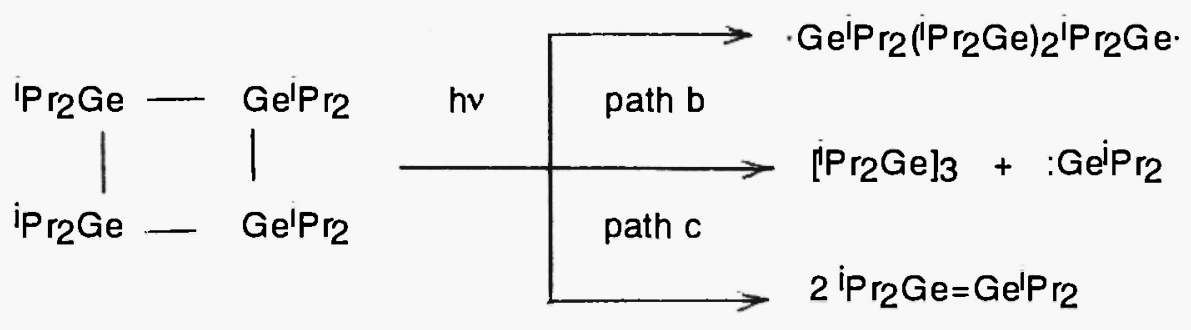

Scheme 4

\section{$\pi$-System-substituted Polygermanes}

The photolysis of phenyl-substituted trigermanes affords a convenient method for generation of germylene species [8]. Irradiation of 1,3-diphenylhexamethyltrigermane in cyclohexane produces dimethylgermylene and 1,2-diphenyltetamethyldigermane. The photolysis of 2-phenylheptamethyltrigermane results in formation of hexamethyldigermane together with phenylmethyldigermylene. When a cyclohexane solution of 2,2-diphenylhexamethyltrigermane is photolyzed, hexamethyldigermane and diphenylgermylene are formed. Photochemically genèrated germylenes are trapped with diene and $\mathrm{CCl}_{4}$ to give the expectec products in high yields.

Trapping experiments, matrix isolation, and laser-flash photolysis studies indicate that the photoreaction of phenyl-substituted trigermanes also involves both the extrusion of germylenes and the formation of germyl radicals. Germyl radicals dimerize to give digermanes.

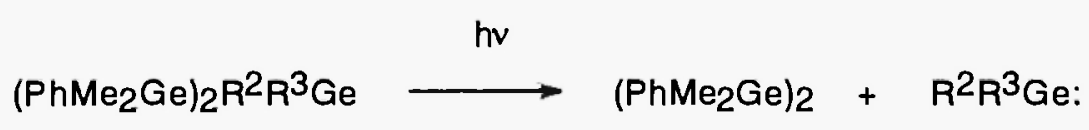

The photolysis of aryldigermanes has been the subject of considerable attention compared with that of aryldisilanes [19]. The photochemical reactions of phenyldigermanes in connection of spectroscopic studies on phenyldigermanes are investigated $[10,11]$.

Diphenyltetramethyldigermane is irradiated with a low-pressure $\mathrm{Hg}$ arc lamp to give phenyt dimethylgermane and diphenyldimethylgermane in low yields. Similar photolysis of diphenyl- 
tetramethyldigermane in the presence of $\mathrm{CCl}_{4}$ to afford phenyldimethylchlorgermane quantitatively. Thus, one of the primary steps of the photolysis of phenylated digermanes is the generation of germyl radicals which can be characterized by laser-falsh photolysis. Laser flash photolysis of phenylated digermanes gives transient bands at $315-330 \mathrm{~nm}$ due to phenyl-substituted germyl radicals [10, 13-15].

On the basis of results in this study, germyl radical pair mechanism shown in Scheme 5 is proposed. The photolysis of phenylated digermanes results in germanium-germanium bond homolysis to give a pair of two germyl radicals. The pair of germyl radicals undego ipsosubstitution, which is a precursor of the germylenes .

Germyl radical pair mechansim is also proposed in photochemical reactions of another $\pi-$ system-substituted digermanes such as benzyldigermanes and styryldigermanes [20]<smiles>[R]C(C)(c1ccccc1)[Ge]([R])(C)c1ccccc1</smiles>

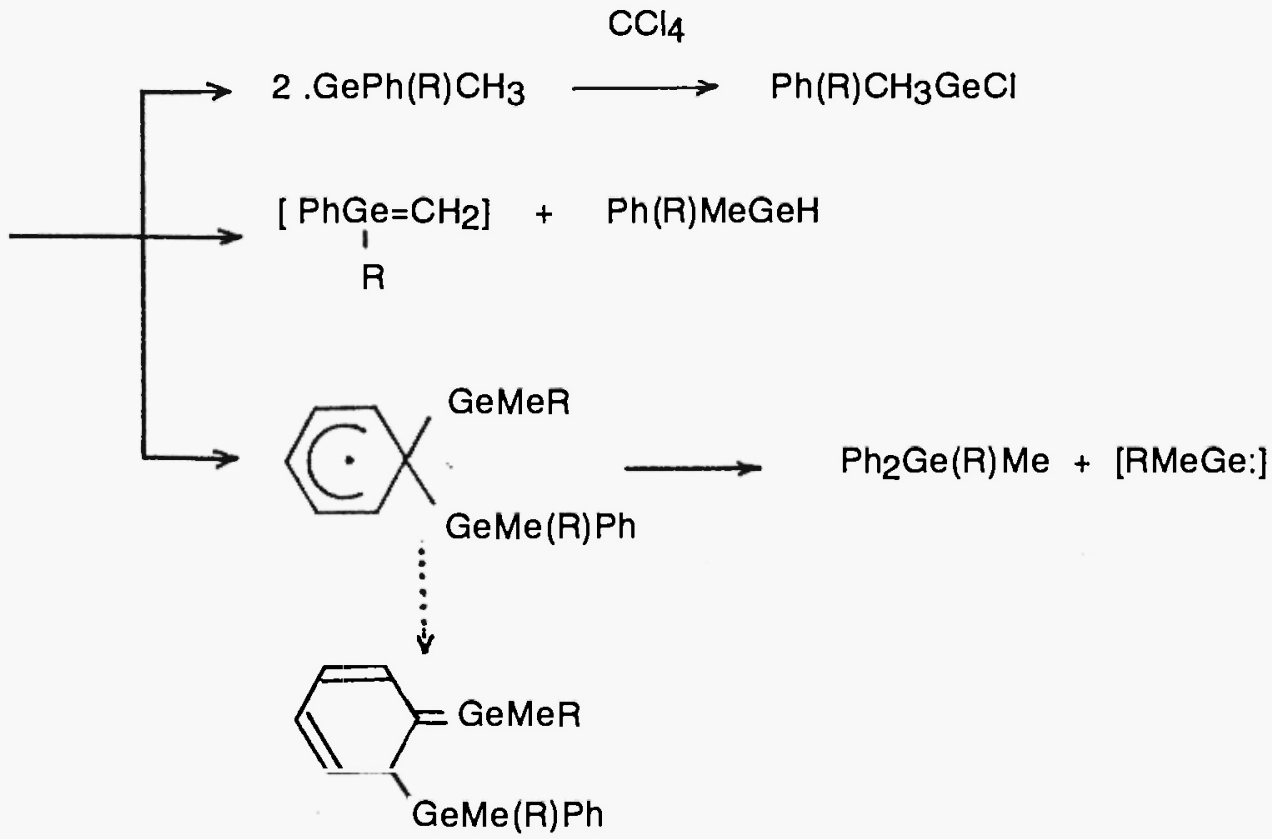

Scheme 5

Ackowledgement. The author wishes to express Drs. Hisaharu Hayashi and Masanobu Wakasa of the Insititute of Physical and Chemical Research (Riken) for measuring laser flash photolysis of polygermanes. This work is supported in part by the Ministry of Education, 
Science, and Culture.

\section{Refreneces}

1. K. Mochida, H. Chiba, and M. Okano, Chem. Lett., (1991), 109.

2. M. Schriewer and W. P. Neumann, J. Am. Chem. Soc., 105 (1983) 897.

3. W. P. Neumann and M. Schriewer, Tetrahedron Lett., 21 (1988) 3273.

4. S. Tomoda, M. Shimoda, Y. Takeuchi, Y. Kaji, K. Obi, I. Tanaka, and K. Honda, J. Chem. Soc., Chem. Commun., (1988) 910.

5. H. Sakurai, K. Mochida, A. Hosomi, and F. Mita, J. Organomet. Chem., 42 (1972) 339.

6. H. Sakura, K. Mochida, and M. Kira, J.Organomet. Chem., 124 (1977) 235.

7. K. Mochida, K. Kimijima, H. Chiba, M. Wakasa, and H. Hayashi, to be published.

8. K. Mochida, I. Yoneda, and M. Wakasa, J. Organomet. Chem., 339 (1990) 53.

9. K. Mochida, N. Kanno, R. Kato, M. Kotani, S. Yamaguchi, M. Wakasa, and H. Hayashi, J. Organomet. Chem., 415 (1991) 191.

10. K. Mochida, M. Wakasa, Y. Sakaguchi, and H. Hayashi, Bull. Chem. Soc. Jpn., 64 (1991) 1899.

11. K. Mochida, H. Kikkawa, and Y. Nakadaira, J. Organomet.Chem., 412 (1991) 9.

12. K. Konieczzy, S. J. Jacobs, J. K. B. Wilking, and J. J. Gaspar, J. Organomet. Chem, 341 (1988) C17.

13. K. Mochida, M. Wakasa, Y. Sakaguchi, and H. Hayashi, J. Am. Chem. Soc., 109 (1987) 7942.

14. H. Hayashi and K. Mochida, Chem. Phys. Lett, 101 (1983) 307.

15. C. Chatilialoglu, K. U. Ingold, J. C. Luszttyk, A. S. Narzen, and J. C. Scaiano, Organometallics, 2 (1983) 1332.

16. K. Mochida and S. Tokura, Bull. Chem. Soc. Jpn., 65 (1992) 1642.

17. K. Mochida, Y. Kawajiri, and M. Goto, Bull. Chem. Soc. Jpn., in press.

18. K. Mochida and S. Tokura, Organometallics, 11 (1992) 2752.

19. M. Ishikawa and M. Kumada, Adv. Organomet. Chem., 19 (1981) 51.

20. K. Mochida, H. Kikkawa, and Y. Nakadaira, Bull. Chem. Soc. Jpn., 64 (1991) 2772.

\section{Received: September 24, 1993}


